\title{
Kajian Penggunaan Batu Gunung Barani Untuk Bahan Campuran AC-BC
}

\author{
Ivon Tambing ${ }^{\star 1}$, Alpius ${ }^{\star 2}$, Louise Elizabeth Radjawane ${ }^{\star 3}$ \\ ${ }^{* 1}$ Mahasiswa Program Studi Teknik Sipil, Universitas Kristen Indonesia Paulus, Makassar \\ Email ivontambing3112@gmail.com \\ *2 Dosen Program Studi Teknik Sipil, Universitas Kristen Indonesia Paulus, Makassar \\ Email alpiusnini@gmail.com \\ *3 Dosen Program Studi Teknik Sipil, Universitas Kristen Indonesia Paulus, Makassar \\ Email eliz louise@yahoo.com
}

\begin{abstract}
ABSTRAK
Penelitian ini bertujuan untuk mengetahui karakteristik batu Gunung Barani, mengetahui komposisi campuran AC-BC dan Stabilitas Marshall Sisa pada campuran AC-BC dengan mengacu pada Spesifikasi Umum 2018. Hasil dari penelitian ini menunjukkan bahwa karakteristik agregat yang berasal dari Gunung Barani Kelurahan Manggau, telah memenuhi spesifikasi menurut Standar Bina Marga 2018. Menurut hasil rancangan komposisi dicampuran AC-BC yang telah menggunakan agregat Gunung Barani, agregat kasar 42,82\%, agregat halus $45,73 \%$, filler 5,45\%, dan kadar aspal optimumnya adalah 6,00\%. Setelah dilakukan pengujian Marshall Konvensional kemudian didapatkan karakteristik campuran beraspal yang telah memenuhi semua standar spesifikasi adalah stabilitas, flow, VIM, VMA, dan VFB dan Marshall Immersion (Stabilitas Marshall Sisa) pada campuran AC-BC yang menggunakan agregat dari Gunung Barani Kelurahan Manggau memenuhi standar/spesifikasi Umum Bina Marga 2018, yaitu minimal 90 \%.
\end{abstract}

Kata Kunci: Karakteristik, AC-BC, Marshall Immersion

\begin{abstract}
This study aims to determine the characteristics of the Mount Barani rock, determine the composition of the AC-BC mixture and the remaining Marshall Stability in the AC-BC mixture by referring to the 2018 General Specifications. The results of this study indicate that the characteristics of the aggregates originating from Mount Barani, Manggau Village, have met specifications according to the 2018 Bina Marga Standard with a coarse aggregate composition design of $42.82 \%, 45.73 \%$ fine aggregate, $5.45 \%$ filler, and the optimum asphalt content is $6.00 \%$. After doing the Conventional Marshall test, the characteristics of the asphalt mixture were obtained that had met all the standard specifications. Marshall Immersion (Marshall Stability Remaining) in the AC-BC mixture using the aggregate from Mount Barani, Manggau Village, meets the General Bina Marga 2018 standard / specification, which is at least $90 \%$.
\end{abstract}

Keywords: Characteristics, AC-BC, Marshall Immersion

\section{PENDAHULUAN}

Dalam menggerakkan roda perekonomian nasional jalan merupakan infrastruktur dasar dan utama, mengingat betapa pentingnya dan strategisnya fungsi jalan dalam mendorong distribusi barang dan jasa sekaligus mobilitas penduduk. Maka dari itu harus adanya perencanaan struktur perkerasan yang kuat, tahan lama dan mempunyai daya tahan tinggi. Pemanfaatan sumber daya alam yang tersedia disekitar area pembangunan jalan sangat dianjurkan, sehingga pemerintah lebih menyarankan untuk menggunakan material sekitar lokasi pembangunan jalan karena penggunaan material di sekitar lokasi pembangunan jalan dinilai lebih efisien baik dari segi biaya maupun waktu. Namun selama ini bahan Perkerasan jalan yang digunakan untuk konstruksi jalan dominan merupakan agregat yang didatangkan dari luar Kabupaten Tana Toraja sehingga membutuhkan dana transportasi material. Kabupaten Tana Toraja merupakan daerah pegunungan sehingga material batu gunung sangat melimpah. Pemanfaatan agregat batu gunung di Kabupaten Tana Toraja belum sepenuhnya digunakan untuk prasarana jalan. Namum belum dimanfaatkan sebagai bahan lapisan perkerasan jalan, khususnya lapisan aspal beton (LASTON).

Di Kabupaten Tana Toraja ada beberapa lokasi sumber agregat yang dapat dimanfaatkan salah satunya di Gunung Barani Kelurahan Manggau Kecamatan Makale yang batu gunungnya belum dimanfaatkan secara maksimal. 
Paulus Civil Engineering Journal

E- Jurnal Teknik Sipil UKI-Paulus Makassar http://ojs.ukipaulus.ac.id/index.php/pcej

Sehingga dalam pemanfaatannya dibutuhkan pemeriksaan terlebih dahulu.

Tujuan penelitian untuk mengetahui nilai karateristik batu Gunung Barani kelurahan Manggau, karakteristik aspal dan berat jenis filler untuk campuran beraspal, mengetahui komposisi campuran AC-BC yang menggunakan agregat batu Gunung Barani, sehingga didapatkan nilai karakteristik campuran AC-BC dengan melalui pengujian Marshall Konvensional dan mengetahui nilai Stabilitas Marshall Sisa (\%) pada Marshall Immersion yang menggunakan agregat batu Gunung Barani Kelurahan Manggau.

Adapun penelitian terkait yang dipublikasikan kadar serat ijuk 2\% untuk campuran AC-BC memiliki nilai perendaman $94,04 \%$ [1], agregat Sungai Wanggar yang digunakan dalam campuran AC-BC memiliki nilai indeks perendaman $94,41 \%$ [2], penggunaan limbah abu bata ringan sebagai filler untuk pengisi kadar aspal 5,7\% memiliki nilai stabilitas tinggi [3], penggunaan slag nikel untuk campuran HRS-Base dalam tes Marshall menghasilkan nilai 97,03\% [4], penggunaan LGA sebagai pengganti aspal minyak memiliki indeks perendaman $95,21 \%$ [5], penambahan semen meningkatkan durabilitas dan stabilitas [6]. Penggunaan agregat sungai Masanda dengan aspal penetrasi $60 / 70$ untuk agregat kasar $42,64 \%$, agregat halus $45,45 \%$, semen (Filler) $5,41 \%$ dengan kadar aspal optimum $6,50 \%$ dimana penelitian tersebut memenuhi standar yang telah ditentukan oleh Bina Marga. [7], agregat sungai Bangkanase dengan aspal penetrasi $60 / 70$ untuk agregat kasar $42,82 \%$, agregat halus $45,73 \%$, semen (Filler) $5,45 \%$ dengan kadar aspal optimum $6,00 \%$ dimana penelitian tersebut memenuhi standar yang telah ditentukan oleh Bina Marga. [8], komposisi campuran untuk Laston AC-BC agregat kasar yaitu $43,13 \%$, agregat halus (pasir) $46,19 \%$, filler $5,53 \%$, dan aspal $5,14 \%$. Untuk campuran Laston AC-WC agregat kasar yaitu 37,05 \%, agregat halus (pasir) $50,60 \%$, filler $5,85 \%$ dan aspal 6,50\%. [9].

Agregat yang digunakan berasal dari Gunung Barani Kelurahan Manggau yang dapat dilihat pada Gambar 1.

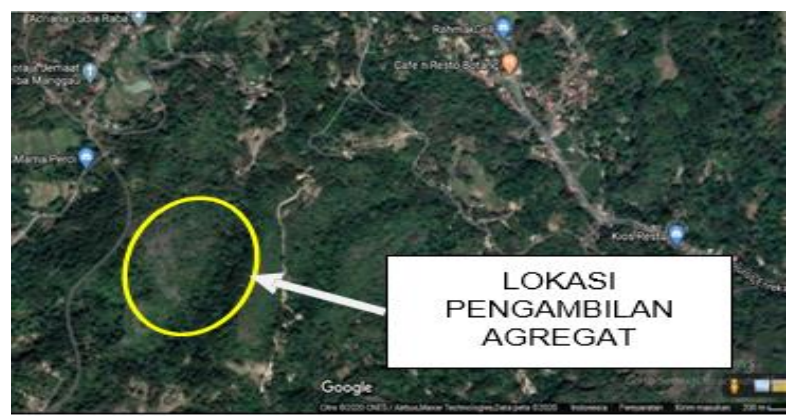

Gambar 1. Lokasi pengambilan material
Volume 3 No.1, Maret, 2021

ISSN Online 2775-4529

\section{METODE}

1. Pemeriksaan Karakteristik Agregat

Pemeriksaan analisa saringan bertujuan untuk memperoleh besaran atau jumlah presentase butiran.

Pemeriksaan Berat Jenis Curah (Bulk) dan Penyerapan Air Agregat Kasar dan Penyerapan Agregat Halus untuk menentukan berat jenis curah, berat jenis permukaan jenuh, berat jenis semu dari agregat, serta angka penyerapan dari agregat.

Pemeriksaan Nilai Setara Pasir untuk mengetahui tingkat kadar presentase kadar lumpur yang terkandung dalam suatu agregat.

Pemeriksaan Keausan Agregat untuk mengetahui angka keausan tersebut, yang dinyatakan dengan perbandingan antara berat bahan aus lolos saringan No.12 $(0,075 \mathrm{~mm})$ terhadap berat semula.

Pemeriksaan Partikel Pipih dan untuk menguji keseragaman agregat.

Pemeriksaan Kelekatan Agregat Pada untuk menentukan kelekatan agregat terhadap aspal.

Pemeriksaan Agregat Lolos Ayakan No.200 untuk mengukur persentase jumlah bahan dalam agregat yang lolos saringan 200 sehingga berguna bagi perencana dan pelaksana pembangunan jalan.

\section{Pemeriksaan Karakteristik Aspal}

Pemeriksaan Penetrasi pada $25^{\circ} \mathrm{C}$ untuk mendapatkan nilai kekerasan aspal dengan melakukan pengujian penetrasi menggunakan alat penetrometer.

Pengujian Daktilitas unutk mengetahui kekenyalan/keplastisan aspal yang dinyatakan dengan panjang pelumaran aspal yang dapat dicapai aspal sebelum putus, pada suhu dan kecepatan tertentu.

Pengujian Titik Lembek Aspal untuk mengetahui suhu dimana aspal mulai lembek dengan menggunakan alat ring and ball dimana suhu ini akan menjadi acuan di lapangan atas kemampuan aspal menahan suhu yang terjadi agar tidak lembek sehingga dapat mengurangi daya lekat.

Pengujian Titik Nyala $\left({ }^{\circ} \mathrm{C}\right)$ untuk mengetahui suhu dimana aspal mulai dapat mengeluarkan nyala dan terbakar akibat pemanasan.

Pengujian Berat Jenis Aspal untuk mengetahui berat jenis aspal yang digunakan.

Pemeriksaan Berat Yang Hilang (\%) untuk mengetahui kehilangan berat pada aspal akibat pemanasan yang berulang dan pengujian ini juga 


\section{http://ojs.ukipaulus.ac.id/index.php/pce}

bertujuan untuk mengukur perubahan kinerja aspal akibat kehilangan berat.

Penetrasi pada $25^{\circ} \mathrm{C}$ TFOT untuk mendapatkan nilai kekerasan aspal yang telah mengalami pemanasan dengan alat Thin Flim Oven Test dengan melakukan pengujian penetrasi menggunakan alat penetrometer, dimana pengujian ini akan menjadi acuan penggunaan aspal di lapangan.

\section{Pemeriksaan Berat Jenis Filler}

Pemeriksaan berat jenis filler digunakan sebagai bahan pengisi campuran aspal.

\section{Rancangan Komposisi Campuran}

Komposisi campuran didasarkan pada gradasi campuran agregat dalam yang dipilih yaitu gradasi ideal atau menggunakan nilai tengah dari rentang gradasi yang digunakan. Komposisi campuran agregat dibagi menjadi tiga fraksi yaitu fraksi agregat kasar, fraksi agregat halus, dan fraksi bahan pengisi.

\section{HASIL DAN PEMBAHASAN}

1. Pemeriksaan Karakteristik Agregat dan Berat Jenis Filler

Tabel 1. Hasil pengujian karakteristik agregat dan berat jenis filler

\begin{tabular}{|c|c|c|c|c|c|c|c|}
\hline \multirow{2}{*}{ No } & \multirow{2}{*}{$\begin{array}{c}\text { Jenis } \\
\text { Pemeriksaan }\end{array}$} & \multirow{2}{*}{ Metode } & \multicolumn{2}{|c|}{ Spesifikasi } & \multirow{2}{*}{ Satuan } & \multirow{2}{*}{$\begin{array}{c}\text { Hasil } \\
\text { Penelitian }\end{array}$} & \multirow{2}{*}{ Keterangan } \\
\hline & & & Min & Maks & & & \\
\hline 1 & $\begin{array}{c}\text { Keausan Agregat } \\
\text { Fraksi A } \\
\text { Fraksi B } \\
\text { Fraksi C } \\
\text { Fraksi D }\end{array}$ & $\begin{array}{l}\text { SNI 2417- } \\
2008\end{array}$ & - & 40 & $\%$ & $\begin{array}{l}4,20 \\
4,84 \\
4,16 \\
5,08 \\
\end{array}$ & Memenuhi \\
\hline
\end{tabular}

Berat Jenis dan

Penyerapan Agregat

$\begin{array}{ccccc}\text { Kasar } & \text { SNI } & & & \\ & 1969- & & & \\ \text { Bulk } & 2016 & 2,5 & - & 2,68 \\ \text { SSD } & & 2,5 & - & 2,71 \\ \text { Apparent } & & 2,5 & - & 2,76 \\ \text { Penyerapan } & & - & 3 & 1,05\end{array}$

2

Penyerapan

Berat Jenis dan

Penyerapan Agregat

Halus

Bulk

SSD

Apparent

Penyerapan

3 Analisa Saringan

1 "

$3 / 4 "$

$1 / 2 "$

$3 / 8$ "

No. 4

No. 8

No. 16

No. 30

No. 50

No. 100

No. 200

PAN

\begin{tabular}{|c|c|c|c|c|c|c|c|}
\hline & PAN & & - & - & & 0.00 & \\
\hline 4 & Berat Jenis Filler & $\begin{array}{c}\text { SNI 03- } \\
1969- \\
1990\end{array}$ & 2,5 & - & & 3,06 & Memenuhi \\
\hline 5 & $\begin{array}{l}\text { Material Lolos Saringan } \\
200\end{array}$ & $\begin{array}{l}\text { SNI } \\
\text { ASTM }\end{array}$ & - & 10 & $\%$ & 1,8 & Memenuhi \\
\hline
\end{tabular}

SNI

1970-

2016

$$
2,5
$$

\section{2,5}

2,5

2,53

2,56

2,62

1,32

$-3$

3

100

94,17

83,44

69,39

54,35

SNI 46

ASTM $\quad 30$

C136- 18

2012

12

12

$7 \quad 20$

$5 \quad 13$

40,98

32,04

Memenuhi

23,32

15,18

9,13

5,03

Memenuhi

Memenuhi

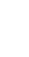




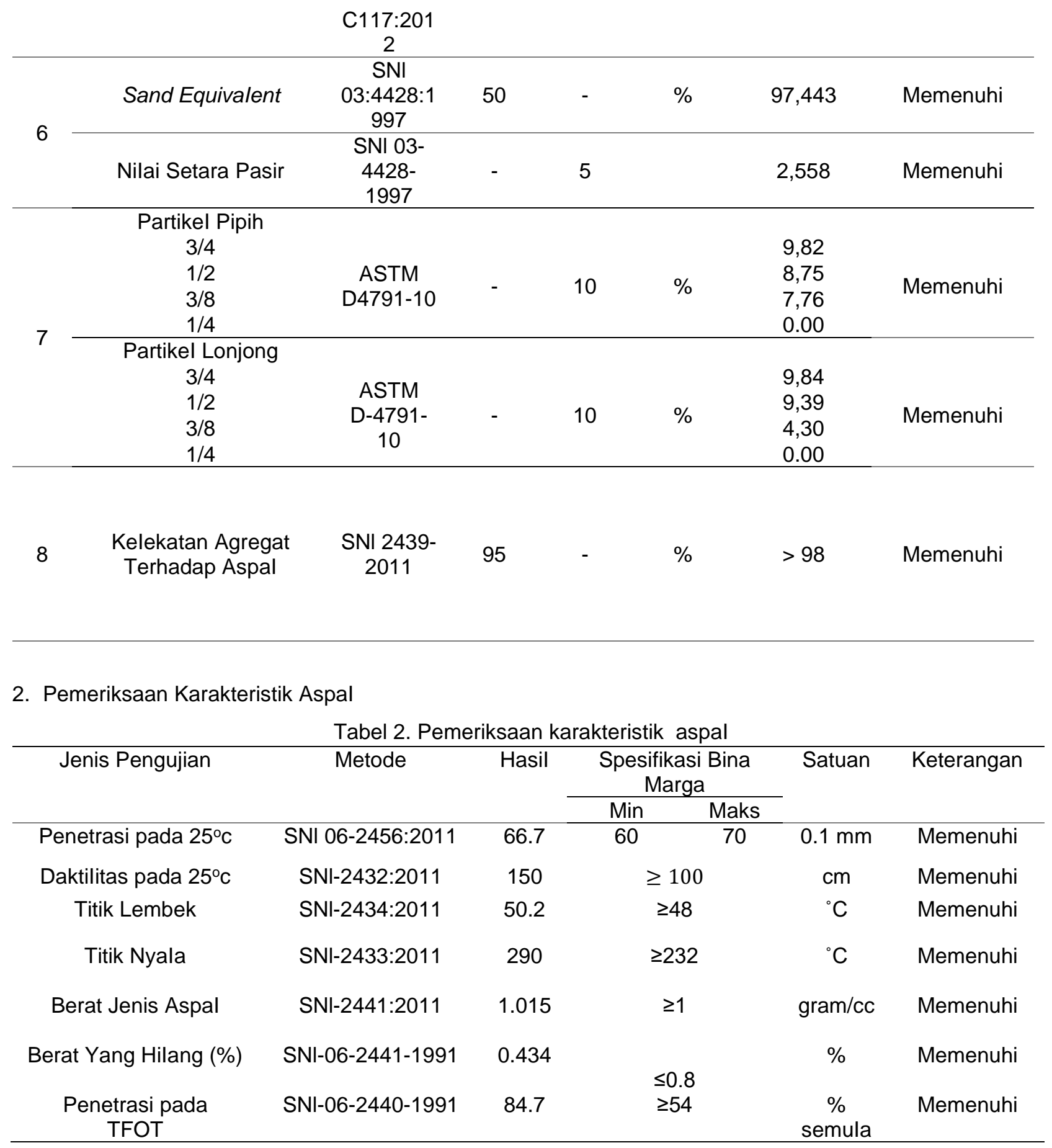

\section{Perancangan Campuran}

Sesuai dengan Spesifikasi Umum Bina Marga 2018 yaitu 5\%, 5,5\%, 6\%, 6,5\%, dan 7\%. Komposisi agregat kasar, agregat halus, dan filler untuk kadar aspal 5\% masing-masing 43,18\%, 46,27\% dan $5,55 \%$. Komposisi agregat kasar, agregat halus, dan filler untuk kadar aspal 5,5\% masing-masing $43,00 \%, 46,00 \%$ dan $5,50 \%$. Komposisi agregat kasar, agregat halus, dan filler untuk kadar aspal $6 \%$ masing-masing $42,82 \%, 45,73 \%$ dan $5,45 \%$.
Komposisi agregat kasar, agregat halus, dan filler untuk kadar aspal 6,5\% masing-masing 42,64\%, $45,45 \%$ dan $5,41 \%$. Komposisi agregat kasar, agregat halus, dan filler untuk kadar aspal 7,00\% masing-masing $42,45 \%, 45,18 \%$ dan $5,36 \%$.

\section{Pembuatan Benda Uji}

Menurut spesifikasi yang telah ditentukan oleh Bina Marga 2018 Untuk suatu campuran harus memenuhi semua standar spesifikasi. Pengujian ini dilakukan dengan alat Marshall Test dan jumlah 
Paulus Civil Engineering Journal

E- Jurnal Teknik Sipil UKI-Paulus Makassar http://ojs.ukipaulus.ac.id/index.php/pcej

benda uji serta penyiapan bahan campuran yang akan digunakan harus sesuai dengan komposisi campuran (Mix Design) yang telah diperoleh.

5. Pengujian Marshall Konvensional

Menurut ASTM D 1559-76 metode Marshall merupakan pemeriksaan stabilitas dan kelelehan/flow, serta untuk menganalisis suatu kepadatan dari pori campuran padat yang telah terbentuk serta benda uji dibentuk dari gradasi agregat campuran tertentu yang sesuai dengan spesifikasi campuran yang telah ada. [10]

\section{Penentuan Kadar Aspal Optimum}

Kadar aspal optimum diperoleh dari nilai terendah grafik hubungan Void In MixNIM. Kadar aspal dalam campuran beton harus memenuhi semua kriteria atau karakteristik. Kadar aspal optimum berasal dari campuran yang dimana memiliki nilai Void In Mix (VIM) terkecil.

\section{Pengujian Marshall Immersion}

Dalam pengujian ini campuran diukur kinerja ketahanannya pada air panas dengan suhu $60^{\circ} \mathrm{C}$ selama 30 menit dan 24 jam.

\section{Stabilitas}

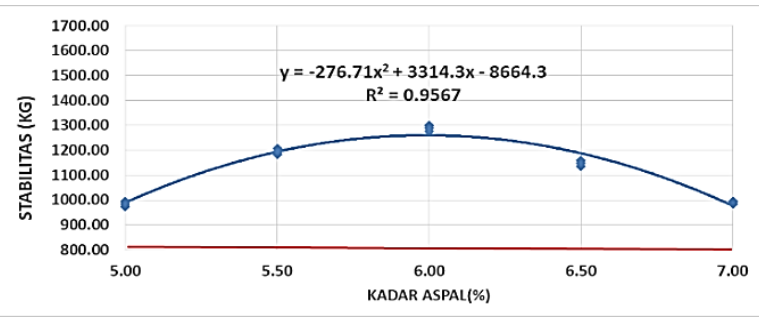

Gambar 2. Hubungan antara kadar aspal dan stabilitas

Berdasarkan grafik diatas persamaan garis $y=-276.71 x^{2}+3314.3 x-8664.3$. Stabilitas naik sebesar 1259,94 $\mathrm{Kg}$ dikadar aspal $6 \%$ dan kemudian kembali turun sebesar $977,01 \mathrm{Kg}$ pada kadar aspal 7\%. Maksimal stabilitas berada pada kadar aspal 5,69\% dengan nilai stabilitas sebesar $1259,94 \mathrm{Kg}$.

Void in Mix (VIM)

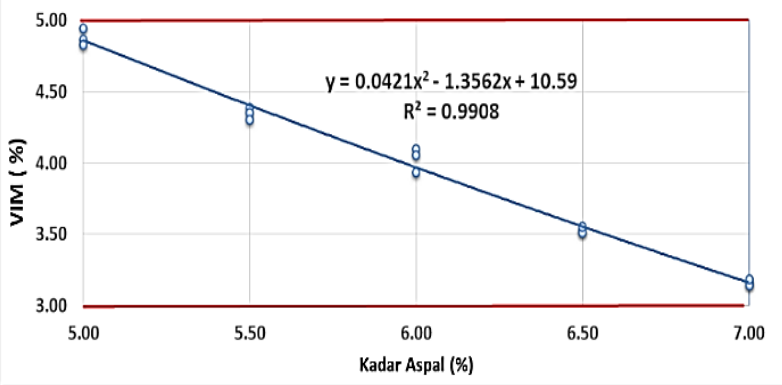

Volume 3 No.1, Maret, 2021 ISSN Online 2775-4529

Gambar 3. Hubungan antara kadar aspal dan VIM Berdasarkan grafik diatas persamaan garis $y=0.0421 x^{2}-1.3562 x+10.59$. VIM turun dikadar aspal $7 \%$ kemudian VIM/Void In Mix berada dibatas minimumnya $3 \mathrm{~mm}$ pada kadar aspal $7 \%$ sedangkan, VIM/Void In Mix mencapai batas maksimum di $5 \mathrm{~mm}$ yang berada pada kadar aspal $4,85 \%$.

\section{Flow}

Berdasarkan grafik diatas persamaan garis $y=0.9238 x^{2}-10.819 x+34.269$. Flow turun dikadar aspal $5.50 \%$ lalu kemudian naik dikadar aspal $7 \%$. Flow minimal harus berada pada kadar aspal $5,66 \%$ dengan nilai flow sebesar $2,61 \mathrm{~mm}$.

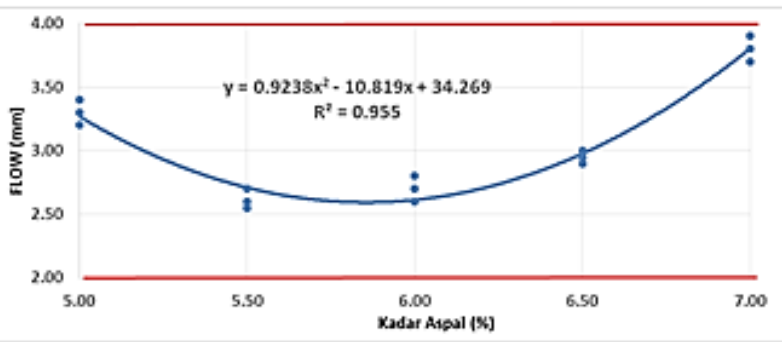

Gambar 4. Hubungan antara kadar aspal dan kelelehan

Void in Mineral Aggregate (VMA)

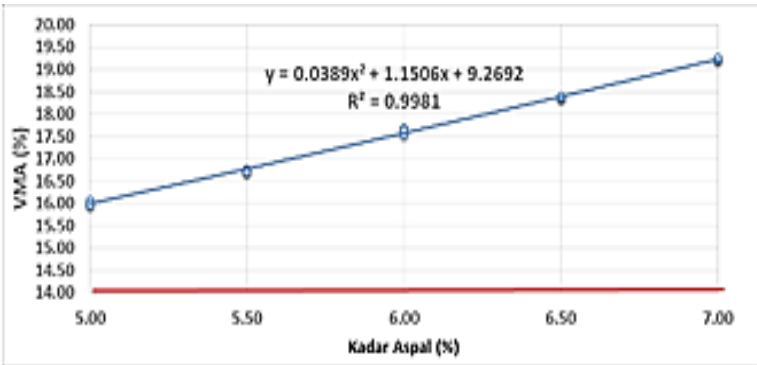

Gambar 5. Hubungan antara kadar aspal dan VMA

Berdasarkan grafik diatas persamaan garis $\mathrm{y}=-0.0389 \mathrm{x}^{2}+1.1506 \mathrm{x}+9.2692$. VMA/ Void in Mineral Aggregate naik dikadar aspal $7 \%$. Kemudian VMA/ Void in Mineral Aggregate terkecil sebesar $14 \%$ dikadar aspal 3,66\%.

Void Filled Bitument (VFB)

Berdasarkan persamaan garis menunjukan $y=-0.8318 x^{2}+16.952 x+5.6499$. VFB/Void Filled Bitument naik dikadar aspal $7 \%$. VFB/ Void Filled Bitument terkecil sebesar $65 \mathrm{~kg} / \mathrm{mm}$ dikadar aspal $4,491 \%$. 


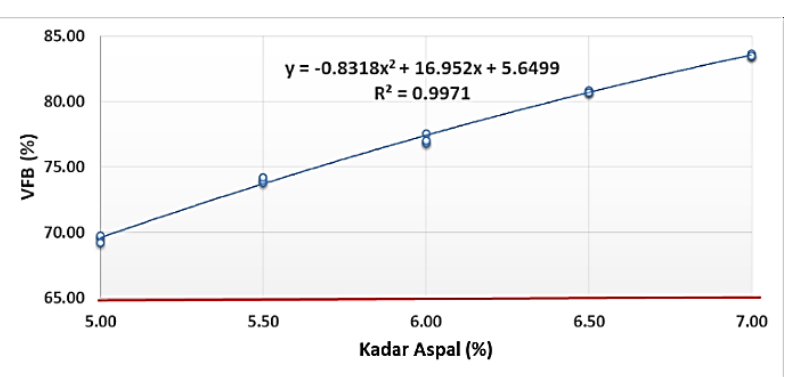

Gambar 6. Hubungan antara kadar aspal dan VFB

Penentuan Kadar Aspal Optimum

Dari hasil analisis karakteristik campuran AC-BC yang telah diuji di laboratorium, rentang kadar aspal yang akan digunakan yaitu $5,00 \%$ sampai $7,00 \%$.

Stabilitas Marshall Sisa
Menurut kadar aspal optimum yang akan digunakan adalah $6,00 \%$ lalu direndam di dalam waterbath \pm 24 jam yang berada pada suhu $\pm 60^{\circ} \mathrm{C}$ agar didapatkan nilai stabilitas Marshall sisa dari campuran. Berdasarkan hasil pengujian Marshall Immersion didapatkan nilai stabilitas Marshall sisa 98,38\% dengan kadar aspal $6 \%$. Dari hasil pengujian tersebut agregat Gunung Barani dalam campuran AC-BC dapat tahan terhadap suhu.

Berdasarkan hasil pengujian karakteristik yang menggunakan agregat Gunung Barani Kelurahan Manggau untuk setiap pengujian karakteristik agregat memenuhi pengujian karakteristik sesuai dengan ketentuan dari Spesifikasi Umum Bina Marga 2018. Berdasarkan rancangan komposisi pada campuran AC-BC yang menggunakan agregat Gunung Barani Kelurahan Manggau diperoleh kadar aspal optimum $6,00 \%$ dengan komposisi campuran agregat kasar $42,82 \%$, agregat halus $45,73 \%$, filler $5,45 \%$.

Tabel 3. Stabilitas Marshall sisa untuk campuran AC-BC

\begin{tabular}{c|rr|c}
\hline \multirow{2}{*}{ Kadar Aspal (\%) } & \multicolumn{2}{|c|}{ Stabilitas } & \multirow{2}{*}{ Stabilitas Marshall Sisa } \\
\cline { 2 - 3 } & Konvensional & Immersion & \\
\hline 6 & 1195.01 & 1195.01 & 100.00 \\
6 & 1183.29 & 1171.57 & 99.01 \\
6 & 1206.72 & 1159.86 & 96.12 \\
\hline Rata-rata & 1195.01 & 1175.48 & 98.38 \\
Minimal & 1183.29 & 1159.86 & 96.12 \\
Maksimal & 1206.72 & 1195.01 & 100.00 \\
\hline
\end{tabular}

\section{KESIMPULAN}

Karakteristik agregat, karakteristik aspal penetrasi 60/70 dan berat jenis filler dari Gunung Barani Kelurahan Manggau, telah memenuhi spesifikasi untuk campuran AC-BC.

Berdasarkan rancangan komposisi pada campuran AC-BC yang menggunakan agregat Gunung Barani Kelurahan Manggau diperoleh kadar aspal optimum $6,00 \%$ d engan komposisi campuran agregat kasar $42,82 \%$, agregat halus $45,73 \%$, filler $5,45 \%$.

Karakteristik campuran AC-BC melalui pengujian Marshall Konvensional diperoleh karakteristik campuran beraspal dan Marshall Immersion (Stabilitas Marshall Sisa) pada campuran AC-BC yang menggunakan agregat dari Gunung Barani Kelurahan Manggau memenuhi standar/spesifikasi Umum Bina Marga 2018, yaitu minimal 90 \%.

\section{DAFTAR PUSTAKA}

[1] Yudi, Angga, dan Alpius, 2020, "Karakteristik Campuran AC-WC dan AC-BC Menggunakan Bahan Tambah Serat ljuk" Paulus Civil Engineering Journal. Vol.1, No.2.

[2] Fani, Irianto, Alpius, (2019), "Pemanfaatan Agregat Sungai Wanggar Kabupaten Nabire Sebagai Bahan Campuran AC-WC dan AC-BC" Paulus Civil Engineering Journal. Vol. 1, No.2.

[3] M. D. M. Palinggi dan Elizabeth, 2020 “Utilization of Lightweight Brick Waste Material As a Mixture of Laston AC - WC." J. of Physics, doi:10.1088/1742-6596/1464/1/012049

[4] A. Kusuma and R. Rachman, 2018, "Study Characteristics of Nickel Slag For Gradient Gap on Mixtured Hot Rolled Sheet Base," International Journal of Innovative Science, Engineering, and Technology Vol. 5, Issue 3

[5] D. P. Randelabi, Alpius dan R. Rachman, 2020, "Pengujian Karakteristik Campuran HRS-Base Menggunakan LGA Sebagai Pengganti Aspal 
Minyak," Paulus Civil Engineering Journal, Vol.2 No.1.

[6] H. Nofrianto dan Z. Hendra, 2014, "Kajian Campuran Panas Agregat Dengan Semen Sebagai Filler Berdasarkan Uji Marshall" Jurnal Momentum Vol. 16, No.2.

[7] ASTM D 1559-76 "Rancangan Campuran Metode Marshall"

[8] Paretanan, Esmi, 2020. Pengujian Karakteristik Campuran AC-BC Menggunakan Batu Sungai Masanda Kabupaten Tana Toraja.Skripsi Teknik Sipil, Universitas Kristen Indonesia Paulus.
[9] Pata, Jozeis Ilen, 2020. Pengujian Karakteristik Campuran AC-BC Menggunakan Batu Sungai Bangkanase Kabupaten Toraja Utara. Skripsi Teknik Sipil, Universitas Kristen Indonesia Paulus

[10] G. P. Palimbunga, R. Rachman, dan Alpius, 2020, "Penggunaan Agregat Sungai Batu Tiakka' pada Campuran AC-BC, Paulus Civil Engineering Journal, vol.2, no.2, hlm. 112-118 